Check for updates

Cite this: RSC Adv., 2017, 7, 45988

\title{
Ultrahigh humidity sensitivity of graphene oxide combined with Ag nanoparticles
}

\begin{abstract}
Ning Li, (D) Xiangdong Chen, ${ }^{*}$ Xinpeng Chen, Xing Ding and Xuan Zhao
Novel capacitive-type humidity sensors with ultrahigh sensitivity based on graphene oxide (GO) combined with Ag nanoparticles (AgNPs) in different concentrations are reported in this study. Various characterization techniques such as transmission electron microscopy (TEM), X-ray diffraction (XRD), water contact angles, and Fourier transform infrared spectroscopy (FTIR) were used to verify the composite formation. The best performance was shown by the GO/Ag (2 wt\%) composite-based sensors, with a sensitivity of $25809 \mathrm{pF} / \% \mathrm{RH}$ in the humidity range from 11\% RH to $97 \% \mathrm{RH}$ and 328 $\mathrm{pF} / \% \mathrm{RH}$ in the humidity range from $11 \%$ to $33 \% \mathrm{RH}$, which was 100 times larger than that of the previous humidity sensor, especially at low humidity levels $(<33 \% \mathrm{RH})$. The Schottky junction theory and complex impedance spectroscopy were employed to understand the underlying sensing mechanisms of the GO/Ag composite towards humidity. The GO/Ag composite was proven to be an excellent candidate for the construction of ultrahigh-sensitivity humidity sensors for various applications.
\end{abstract}

Received 22nd June 2017

DOI: $10.1039 / \mathrm{c} 7 \mathrm{ra06959f}$

rsc.li/rsc-advances

method. However, since it is restricted to natural GO, all the previous GO humidity sensors have limited sensitivity at low humidity levels and are hardly able to meet the abovementioned needs.

Incorporation of metal nanoparticles into inorganic semiconductors or polymers is an effective method for enhancing the function of materials. ${ }^{17-19} \mathrm{Ag}$ nanoparticles/nanowires and their composites with semiconductors or polymers have been used to fabricate humidity sensors. Dzhafarov et al. ${ }^{20}$ found that the open-circuit voltage of a Ag porous $\mathrm{Si}-\mathrm{Si}$ substrate interface changed linearly with variations in the humidity. Power et al. ${ }^{21}$ prepared Ag nanoparticles stabilized with polyvinyl alcohol and revealed the rapid humidity response of these nanoparticles. $\mathrm{Lu}$ et $a l^{22}$ fabricated Ag nanowires with DNA as a template and reported that the Ag-DNA network showed a current increase of more than $400 \%$. Wang et $a .^{23}$ fabricated sensors based on NAgraphene modified with $\mathrm{Ag}$ nanoparticles, which showed a fast response speed ( $\sim 1$ second). Therefore, the combination of $\mathrm{Ag}$ and GO could be expected to create new functional nanocomposites with excellent humidity sensing properties.

In the present study, the development of an excellent humidity-sensing layer based on the GO/Ag composite utilizing simple physical blending methods has been reported for the first time. The composites were extensively characterized using different material characterization techniques. The humidity sensing properties of the proposed sensors were investigated over a wide range of $11-97 \%$ relative humidity at room temperature. The proposed sensors exhibited unprecedented sensitivity. The influence of different proportions of Ag nanoparticles in the composites on the sensing property was 
investigated. Moreover, the possible humidity-sensing mechanism has been discussed in detail.

\section{Experimental}

\section{GO/Ag composites}

All the chemicals were of analytical grade and purchased from Xianfeng-nano company. The GO dispersion $\left(1 \mathrm{mg} \mathrm{ml}^{-1}\right)$ and $\mathrm{Ag}$ nanoparticle dispersion $\left(0.1 \mathrm{mg} \mathrm{ml}^{-1}\right)$ with a grain size of $20 \mathrm{~nm}$ were ultrasonically treated for $30 \mathrm{~min}$ before use; then, AgNPs at various weight percentages $(0.5,1,1.5$, and $2 \mathrm{wt} \%)$ were added to the GO dispersion, ${ }^{52}$ which was sonicated to achieve a uniform dispersion of nanoparticles. The final product has been denoted as $\mathrm{GO} / \mathrm{Ag}(\mathrm{X})$, where $\mathrm{X}$ represents the different weight percentages of $\mathrm{Ag}$ to GO. Interdigitated electrodes (IDEs) were fabricated on a N-doped silicon wafer with a top layer of $\mathrm{SiO}_{2}(300 \mathrm{~nm})$ formed as an insulating layer. Ti/Au layers with a thickness of $100 \mathrm{~nm} / 400 \mathrm{~nm}$ were deposited on the $\mathrm{SiO}_{2}$ layer using magnetron sputtering. Au electrodes with a $50 \mu \mathrm{m}$-wide gap were prepared through photoetching followed by wet etching. Before the fabrication of the sensing films, the IDEs were rinsed with distilled water and ethanol and dried under $\mathrm{N}_{2}$ overnight. To perform the humidity tests, $0.4 \mathrm{ml}$ of each sample was drop-cast on the IDEs through a micro-syringe, followed by drying at room temperature under $\mathrm{N}_{2}$ for 2 hours.

\section{Characterization}

Transmission electron microscopy (TEM) images were obtained using the FEI/Philips Tecnai 12 BioTWIN transmission electron microscope. The water contact angles were measured using the Kruss DSA 25 drop shape analyzer. The X-ray diffraction measurements of $\mathrm{GO}, \mathrm{Ag}$, and $\mathrm{GO} / \mathrm{Ag}$ were performed using an X'Pert Pro MPD X-ray diffraction instrument (PANalytical Co., Holland) at $40 \mathrm{kV}$ and $35 \mathrm{~mA}$. Infrared spectra were obtained via a Bruker Tensor 27 FT-IR spectrophotometer (Bruker Corporation, Germany) using $\mathrm{KBr}$ as a carrier. The humidity sensing properties were investigated by exposing the $\mathrm{GO} / \mathrm{Ag}$ film sensor to various relative humidity (RH) levels, which were achieved using

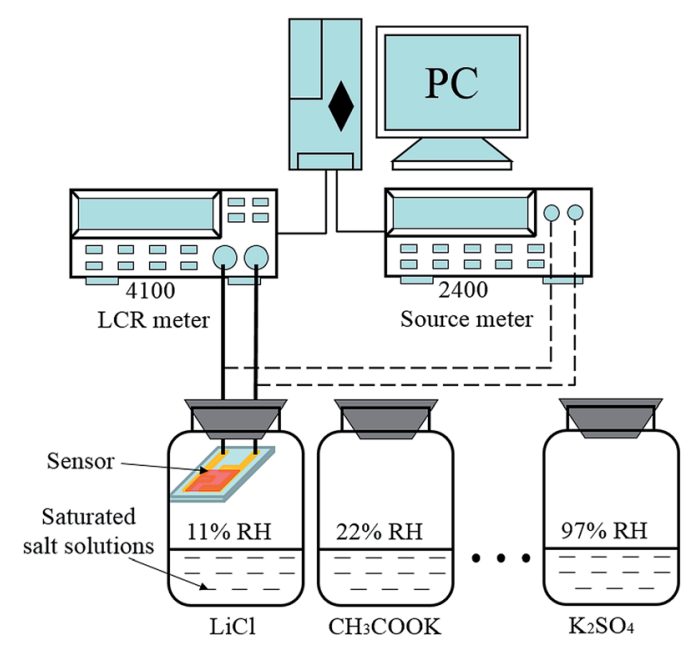

Fig. 1 Schematic of the experimental set-up. several saturated aqueous solutions. The saturated aqueous solutions in a closed vessel at a stable temperature can provide stable and controllable $\mathrm{RH}$ levels in their equilibrium states. Hence, saturated solutions of $\mathrm{LiCl}, \mathrm{CH}_{3} \mathrm{COOK}, \mathrm{MgCl}_{2}, \mathrm{~K}_{2} \mathrm{CO}_{3}$, $\mathrm{Mg}\left(\mathrm{NO}_{3}\right)_{2}, \mathrm{CuCl}_{2}, \mathrm{NaCl}, \mathrm{KCl}, \mathrm{KNO}_{3}$, and $\mathrm{K}_{2} \mathrm{SO}_{4}$ in a closed vessel were used to obtain approximately $11 \%, 23 \%, 33 \%, 43 \%, 54 \%$, $62 \%, 75 \%, 85 \%, 93 \%$, and $97 \% \mathrm{RH}$ levels, respectively. The capacitance response and ac complex impedance spectroscopy of the presented sensors were measured using an LCR meter (Wayne Kerr, 4100, UK), which was connected to a PC through a LAN interface. The current-voltage $(I-V)$ curves of the sensors were obtained using a source meter (Keithley, 2400, USA). A schematic of the experimental set-up used for the humiditysensing measurement is illustrated in Fig. 1.

\section{Results and discussion}

\section{Structure and morphology}

During the humidity-sensing process, it was found that $\mathrm{GO} / \mathrm{Ag}$ ( $2 \mathrm{wt} \%$ ) showed the maximum response. Thus, we tried to highlight the morphology as well as carry out a structural analysis of this sample through our characterizations.

Fig. 2(a and b) show the TEM images of GO/Ag (2 wt\%) and pure GO, where the latter appears rougher. Sufficient AgNPs can be observed in the $\mathrm{GO} / \mathrm{Ag}$ composite films, and they can also be recognized clearly in the high-resolution TEM image (Fig. 2(c)). Moreover, many more wrinkles can be observed in the $\mathrm{GO} / \mathrm{Ag}$ films. All these nanostructures of the $\mathrm{GO} / \mathrm{Ag}$ films provide a large specific surface area, which is beneficial for the adsorption of water molecules. Through measuring the wettability, the water contact angles were found to be about $49.6^{\circ}$ and $27.8^{\circ}$ for pure $\mathrm{GO}$ and $\mathrm{GO} / \mathrm{Ag}$ ( $2 \mathrm{wt} \%$ ), respectively, as shown in Fig. 2(d and e), indicating that the composites were more hydrophilic, ${ }^{24}$ consistent with their nanostructures.

XRD was performed to investigate the phase structure of GO, $\mathrm{Ag}$, and $\mathrm{GO} / \mathrm{Ag}$ (2 wt\%) (Fig. 3(a)). Pure GO displayed a typical characteristic (002) peak at $10.81^{\circ}$. In the XRD pattern of the pure AgNPs, the peaks at $2 \theta=37.7^{\circ}, 43.7^{\circ}, 64.8^{\circ}, 77.8^{\circ}$, and $81.27^{\circ}$ can be assigned to the (111), (200), (220), (311), and (222)

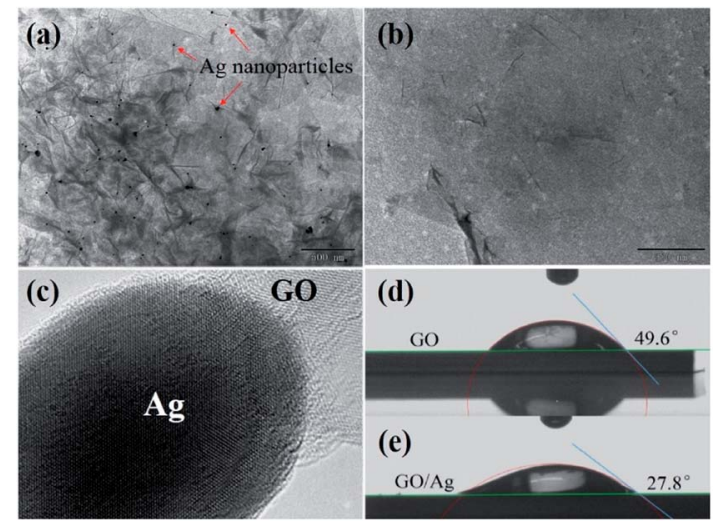

Fig. 2 TEM characterization of (a) GO/Ag and (b) GO. (c) High-resolution TEM characterization of GO/Ag. The water contact angles of (d) $\mathrm{GO}$ and (e) GO/Ag. 
crystalline planes of silver, respectively. These diffraction peaks are in agreement with the standard card (JCPDS: 04-0783). ${ }^{25}$ The diffraction peaks of $\mathrm{GO} / \mathrm{Ag}$ are in good agreement with the standard Ag, except for the broad (002) peak at approximately $10.8^{\circ}$, which can be indexed to the disordered stacked graphitic sheets. No peaks from other phases were detected; thus, the product was considered to be of high purity.

XPS analysis was performed to investigate the chemical state of the GO/Ag composite. In Fig. 3(d), the survey spectra clearly indicate the existence of $\mathrm{C}, \mathrm{O}$, and $\mathrm{Ag}$ in $\mathrm{GO} / \mathrm{Ag}$. The $\mathrm{C} 1 \mathrm{~s}$ and $\mathrm{Ag}$ 3d XPS core level spectra of the GO-Ag nanocomposite are shown in Fig. 3(b and c), respectively. The $\mathrm{C}$ 1s core level XPS spectrum can be deconvoluted into four components with the binding energies at 285.0, 287.1, 288.5, and $289.3 \mathrm{eV}$ assigned to $\mathrm{C}=\mathrm{C}, \mathrm{C}-\mathrm{O}, \mathrm{C}=\mathrm{O}$, and $\mathrm{HO}-\mathrm{C}=\mathrm{O}$, respectively (Fig. 3(b)). These results indicate that there are a large number of functional groups on the surface of the GO nanosheets. The intensity of the band at $287.1 \mathrm{eV}(\mathrm{C}-\mathrm{O})$ decreased; this indicated the partial reduction of GO nanosheets to graphene nanosheets. As shown in Fig. 3(c), the XPS spectra clearly show the concision of elemental $\mathrm{Ag}$ and the elemental status of $\mathrm{Ag}$ (3d). The $\mathrm{Ag}$ (3d) peaks are a doublet, which arises from spin-orbit coupling $\left(3 \mathrm{~d}_{5 / 2}\right.$ and $\left.3 d_{3 / 2}\right) .{ }^{47}$ The binding energies of the $A g 3 d_{5 / 2}$ and $A g 3 d_{3 / 2}$ peaks are 368.76 and $374.79 \mathrm{eV}$, respectively, which clearly prove that silver is present only in the metallic form; this indicates the formation of AgNPs on the surface of the GO nanosheets. Fig. 3(d) also shows the XPS spectra of GO/Ag (2 wt\%) after water
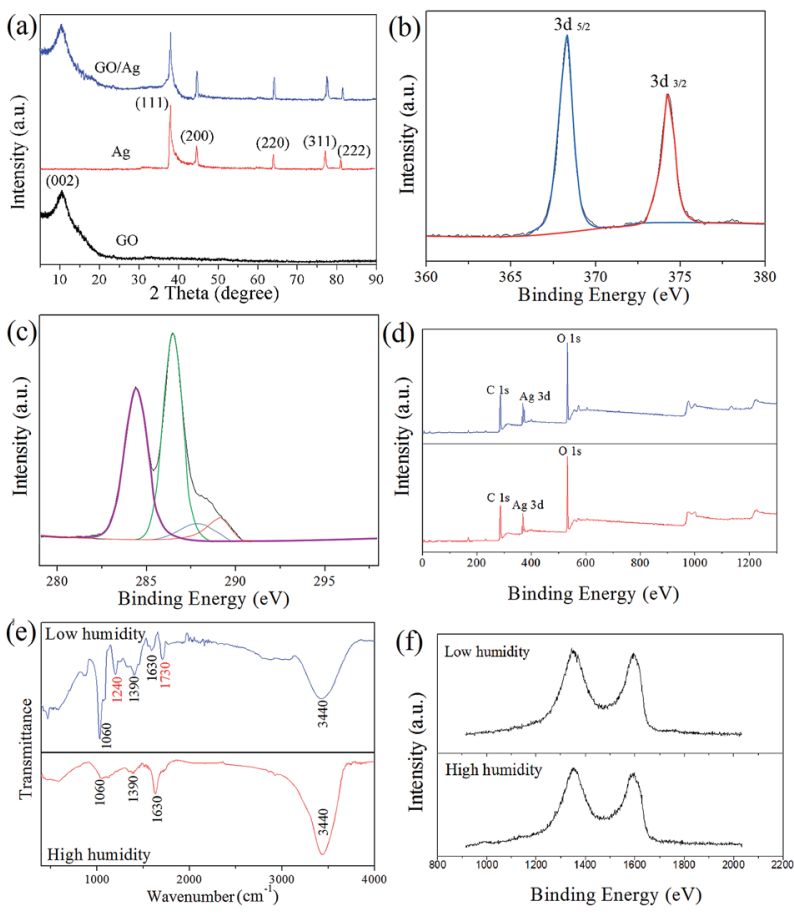

Fig. 3 (a) XRD spectra for GO, Ag, and GO/Ag. (b) C 1s XPS spectrum of GO-Ag. (c) Ag 3d core level spectrum of GO/Ag. (d) XPS survey scans of $\mathrm{GO} / \mathrm{Ag}$ before and after the humidity sensing process. (e) FT-IR spectra and (f) Raman spectra of GO/Ag at low and high humidity environments. molecule adsorption, and it indicates that the adsorption process does not change the chemical state of $\mathrm{GO} / \mathrm{Ag}$.

Fig. 3(e) shows the FT-IR spectra of the GO/Ag (2 wt\%) thin film in the range of 400-4000 $\mathrm{cm}^{-1}$ under low and high humidity environment. As shown in Fig. 3(e), a characteristic absorption peak of GO appeared at $3440 \mathrm{~cm}^{-1}$ because of the presence of $-\mathrm{OH}$ groups. The peaks between 1800 and $1050 \mathrm{~cm}^{-1}$ are due to $\mathrm{C}=\mathrm{O}$ stretching, $\mathrm{C}-\mathrm{H}$ stretching, $\mathrm{C}-\mathrm{OH}$ stretching, C-O-C stretching, and C-O stretching at 1730, 1630, 1396,1240 , and $1060 \mathrm{~cm}^{-1}$, respectively. ${ }^{26}$ These results indicate that the $\mathrm{GO} / \mathrm{Ag}$ films are covered with oxygen functional groups. According to the spectra of $\mathrm{GO} / \mathrm{Ag}$, the peaks at 1730 and $1240 \mathrm{~cm}^{-1}$ are absent at high humidity. This might be explained as follows: under a high humidity environment, during the water molecule adsorption process, $\mathrm{C}=\mathrm{O}$ and $\mathrm{C}-\mathrm{O}-\mathrm{C}$ are combined with water molecules and converted to $\mathrm{C}-\mathrm{OH}$. Based on the XPS and FTIR characterizations, it can be concluded that this conversion process is reversible.

The attachment of silver nanoparticles on the GO sheets was also investigated by Raman spectroscopy. This technique is a powerful tool for investigating ordered and disordered nanocarbons. The Raman spectrum of GO/Ag was characterized by the presence of bands at $1320 \mathrm{~cm}^{-1}$ (D band) and $1570 \mathrm{~cm}^{-1}$ ( $\mathrm{G}$ band) under low and high humidity environments, respectively, as shown in Fig. 3(f). A laser operating at $532 \mathrm{~nm}$ was used as the excitation source. The $\mathrm{D}$ band is active in the presence of defects in the graphitic structure. ${ }^{48}$ The $\mathrm{G}$ band corresponds to the first-order bond stretching of $\mathrm{sp}^{2}$ carbon atoms $\left(\mathrm{E}_{2 \mathrm{~g}}\right)$ and is related to the graphitic mode. The ratio ID/IG of GO/Ag was 1.13 and basically remained the same under both low humidity and high humidity environments.

\section{Humidity-sensing results}

For clearly contrasting the performance of all the samples, the sensitivity of the samples towards humidity was defined as follows:

$$
S=\frac{C_{\mathrm{RH}}-C_{\text {initial }}}{\mathrm{RH}^{0}-\mathrm{RH}_{\text {initial }} \%}
$$

where $S$ denotes the sensitivity, $C_{\mathrm{RH}}$ denotes the capacitance of the sensor at the current $\mathrm{RH}$ levels, and $C_{\text {initial }}$ is the initial capacitance. According to the experiment, we chose the initial state of the sensors as that at the $11 \%$ RH level. Fig. 4(a) shows a comparison of the sensitivity of the samples towards humidity. As can be seen, the capacitance of all the samples increased with the increasing $\mathrm{RH}$. Under the same $\mathrm{RH}$ condition, the capacitance of the sensing materials tended to increase with the increasing Ag content. The sensitivity of GO/Ag (2 wt\%) was more than 22 times that of pure GO. As shown in Table 1, the sensing property of the GO/Ag (2 wt\%) samples was comparable to those of capacitive-type humidity sensors proposed in previous studies. ${ }^{27-32}$ This comparison highlights the unprecedented performance of $\mathrm{GO} / \mathrm{Ag}$ ( $2 \mathrm{wt} \%$ ) as a candidate for constructing humidity sensors, with large variations of output capacitance from $1050 \mathrm{pF}$ to $2220624 \mathrm{pF}$ and a sensitivity of $25809 \mathrm{pF} / \% \mathrm{RH}$, which is a 100 times larger than that of 

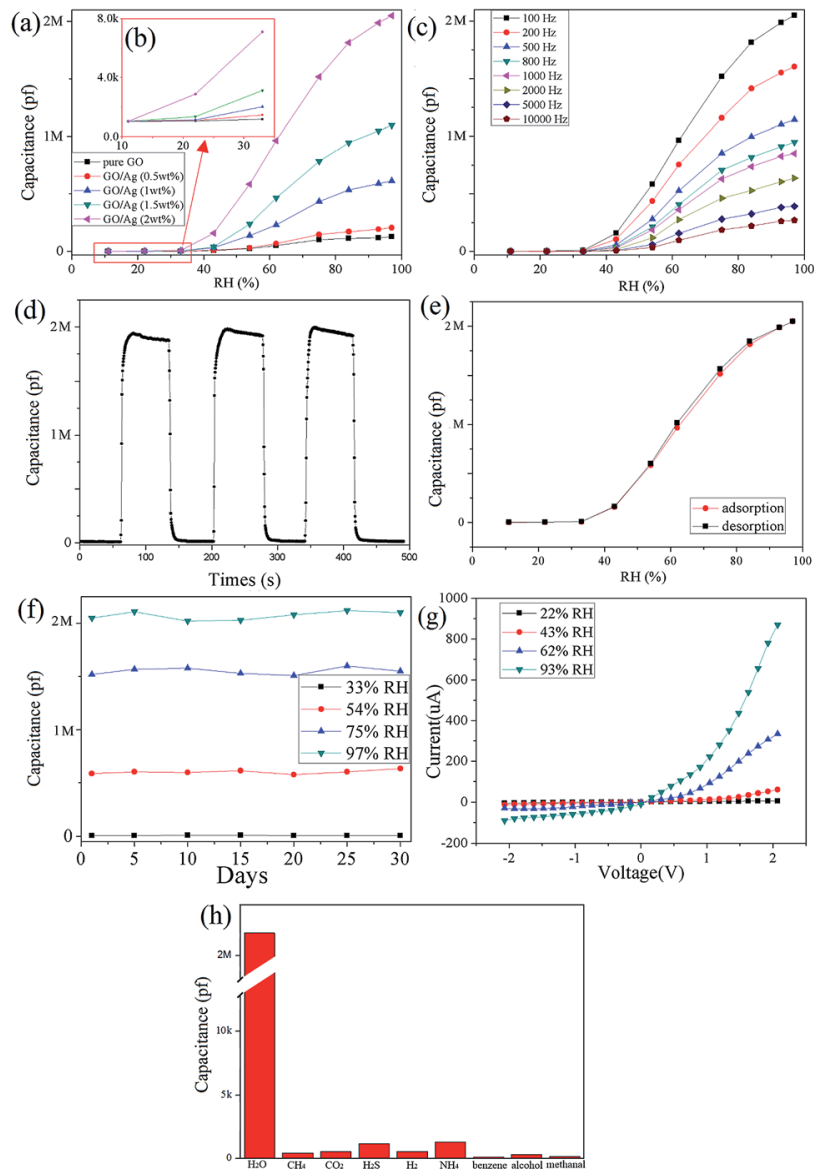

Fig. 4 (a) Capacitance dependence on the relative humidity of pure $\mathrm{GO}$ and $\mathrm{GO} / \mathrm{Ag}(\mathrm{X}), \mathrm{X}: 0.5 \mathrm{wt} \%, 1 \mathrm{wt} \%, 1.5 \mathrm{wt} \%$, and $2 \mathrm{wt} \%$. (b) At low humidity levels $(<33 \% \mathrm{RH})$. (c) Relationship between impedance and $\mathrm{RH}$ at different frequencies based on GO/Ag (2 wt\%). (d) Response and recovery curve of the sample GO/Ag (2 wt\%). (e) Hysteresis characteristic of the sample GO/Ag (2 wt\%). (f) Long-term stability of the GO/ $\mathrm{Ag}(2 \mathrm{wt} \%)$-based sensor exposed to $33 \%, 54 \%, 75 \%$, and $97 \% \mathrm{RH}$. (g) Measured I-V curves of the sample GO/Ag (2 wt\%) at various $\mathrm{RH}$ levels. (h) Selectivity performance of GO/Ag (2 wt\%).

previous capacitive humidity sensors such as polyimide humidity sensors. ${ }^{29}$ Fig. 4(b) indicates the capacitive responses of all the sensors at low humidity $(<33 \%)$. The sensitivity of GO/ $\mathrm{Ag}$ (2 wt\%) (328 pF/\% RH from 11\% to 33\% RH) was much higher than that of pure $\mathrm{GO}(8.7 \mathrm{pf} / \% \mathrm{RH}$ from $10 \%$ to $33 \% \mathrm{RH})$.
This result reveals the excellent sensitivity of $\mathrm{GO} / \mathrm{Ag}$ under environments with low RH levels, which can extend the applications of sensors.

It should be pointed out that although the sensitivity of the composite is proportional to the ratio of $\mathrm{Ag}$, the ratio has a limit. $\mathrm{Ag}$ nanoparticles are a good conductor. When the proportion of $\mathrm{Ag}$ nanoparticles in the composites is too much, the initial resistance of the composites becomes too small to be dielectric. This phenomenon can be explained through percolation thresholds. ${ }^{33}$

The relationship between capacitance and $\mathrm{RH}$ at various frequencies for GO/Ag ( $2 \mathrm{wt} \%$ ) is shown in Fig. 4(c). The results showed that the capacitance increased with the increasing $\mathrm{RH}$ (especially at $\mathrm{RH}>43 \%$ ) in the low-frequency region and then became nearly independent of $\mathrm{RH}$ in the high-frequency region (i.e. between 5 and $10 \mathrm{kHz}$ ). These results indicated that the capacitance was simultaneously dependent on the frequency and $\mathrm{RH}$. According to the literature, ${ }^{34}$ the polarization of adsorbed water molecules occurs in the low-frequency region, whereas the electrical field changes direction rapidly in the high-frequency region. The polarization speed of the water molecules cannot cope with these changes; consequently, the capacitance becomes small and independent of the $\mathrm{RH}$ in the high-frequency region. As observed, the curve displayed the best linearity at $100 \mathrm{~Hz}$. Thus, the frequency of $100 \mathrm{~Hz}$ was determined as the operation frequency for assessing the other humidity-sensing properties of GO/Ag ( $2 \mathrm{wt} \%)$. The response and recovery behaviour represent a significant basis for assessing the performance of humidity sensors. Fig. 4(d) shows the response-recovery characteristic of GO/Ag ( $2 \mathrm{wt} \%$ ). The time taken by a sensor to achieve $90 \%$ of the total impedance change is defined as the response time in the case of adsorption and the recovery time in the case of desorption. The measured response and recovery times were approximately 8 and $12 \mathrm{~s}$, respectively. Compared with traditional-sensing-materials-based sensors, ${ }^{27,29}$ $\mathrm{GO} / \mathrm{Ag}$ exhibited significantly reduced response times and recovery times. Furthermore, the capacitance can be fully restored to the initial capacitance value. Large humidity hysteresis has long been a serious problem in humidity sensors. The hysteresis (between humidification and desiccation and measured over an $\mathrm{RH}$ range of $10-90 \% \mathrm{RH}$ ) was less than $5 \%$ RH (Fig. 4(e)), which corresponds to $65 \%$ RH. This result indicated that the hysteresis of GO/Ag ( $2 \mathrm{wt} \%$ ) was relatively low. The rapid response and recovery might have played an

Table 1 Comparison of the sensitivities for different humidity sensing materials reported in the literature and in this study

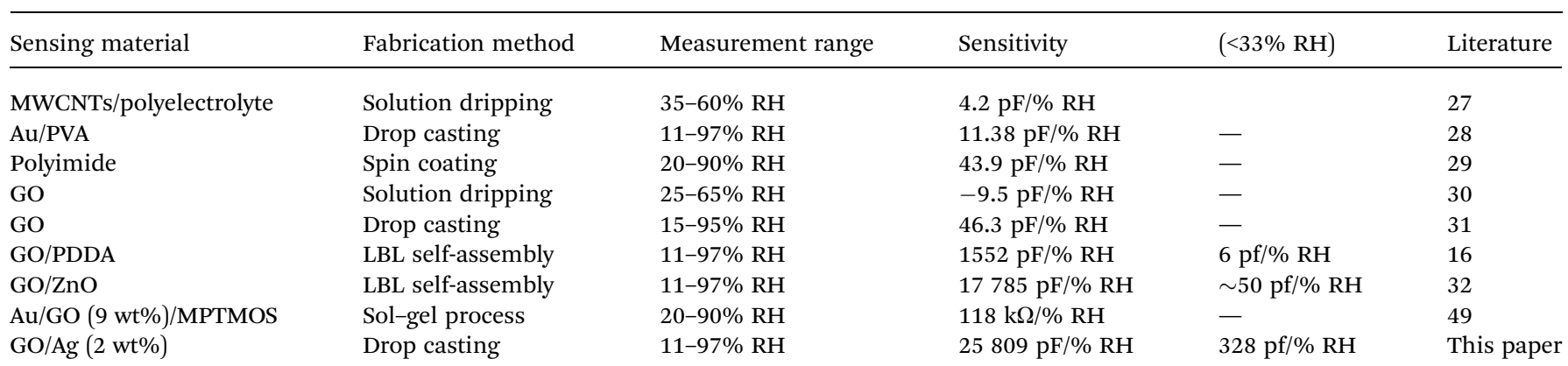


important role in weakening the hysteresis. Stability is an important parameter of humidity-sensing properties. The capacitance of $\mathrm{GO} / \mathrm{Ag}$ ( $2 \mathrm{wt} \%$ ) was tested repeatedly under fixed humidity levels over a period of 5 days. The results are shown in Fig. 4(f). The capacitance variation is less than $4 \%$ in each humidity region for 1 month at $100 \mathrm{~Hz}$, which shows good longterm stability. The current-voltage $(I-V)$ curves of GO/Ag ( $2 \mathrm{wt} \%)$ (p-GO/Ag hybrid device) at various $\mathrm{RH}$ levels are shown in Fig. 4(h). Both the forward and reverse currents in the device increased with the increasing RH. However, the reverse currents were small; this indicates a better rectifying behaviour of the Schottky junction. ${ }^{32}$ The selectivity performance of the samples should be investigated to avoid the influence of other reducing and oxidising gases and vapours. The capacitance of $\mathrm{GO} / \mathrm{Ag}$ (2 wt\%) was tested with $\mathrm{H}_{2}, \mathrm{CH}_{4}, \mathrm{CO}_{2}, \mathrm{H}_{2} \mathrm{~S}, \mathrm{NH}_{4}$, benzene, alcohol, and methanal vapours with the same high concentration of $5000 \mathrm{ppm}$ at room temperature to investigate the selectivity towards $\mathrm{H}_{2} \mathrm{O}$, and the results are shown in Fig. $4(\mathrm{~g})$. The benzene, alcohol, and methanal vapours were prepared by a liquid evaporation method ${ }^{50}$ with $\mathrm{N}_{2}$ as the carrier gas. It is clearly observed that the test samples have extremely higher sensitivity towards $\mathrm{H}_{2} \mathrm{O}$ than towards other test gases. The good selectivity of the $\mathrm{GO} / \mathrm{Ag}$ samples might be attributed to the ion conduction benefit from the absorption of water molecules.

\section{Humidity-sensing mechanism}

The electrical response of the sensing materials to humidity is related to the physical adsorption of water molecules. To interpret the relationship between the capacitance and the $\mathrm{RH}$, the following eqn (2) was adopted to depict the relationship: ${ }^{35}$

$$
C=\left(\varepsilon_{\gamma}-\mathrm{i} \gamma / \omega \varepsilon_{0}\right) C_{0}
$$

where $\gamma$ denotes the conductance, $\omega$ denotes the frequency, and $i$ is the imaginary constant. According to this expression, the capacitance of the sensing material is proportional to $\gamma$ and inversely proportional to $\omega$. In addition, $\gamma$ is related to the physisorption of water molecules in the sensing material such that different sorption processes yield different $\gamma$ values. $\gamma$ increases with the increasing $\mathrm{RH}$; thus, the capacitance increases with the increasing $\mathrm{RH}$ depending on the frequency. ${ }^{35}$

i. Adsorption process of water molecules on GO/Ag materials. At low $\mathrm{RH}$, water molecules are primarily physisorbed onto the available active sites (hydrophilic groups and vacancies) of the GO surface through double hydrogen bonding, as shown in Fig. 5(a). In this regime, the water molecules are unable to move freely because of restriction from the double hydrogen bonding. The hopping transfer of protons between adjacent hydroxyl groups in the first-layer physical adsorption of water requires a lot of energy; hence, the GO films mainly exhibit intrinsic conductance.

As the RH increases, water molecules are physisorbed through single hydrogen bonding on the hydroxyl groups. Moreover, the water molecules permeate into the interior of GO layers (Fig. 5(b)). Thereafter, the water molecules become mobile and progressively become identical to those in the bulk liquid. Moreover, the physisorbed water molecules gradually

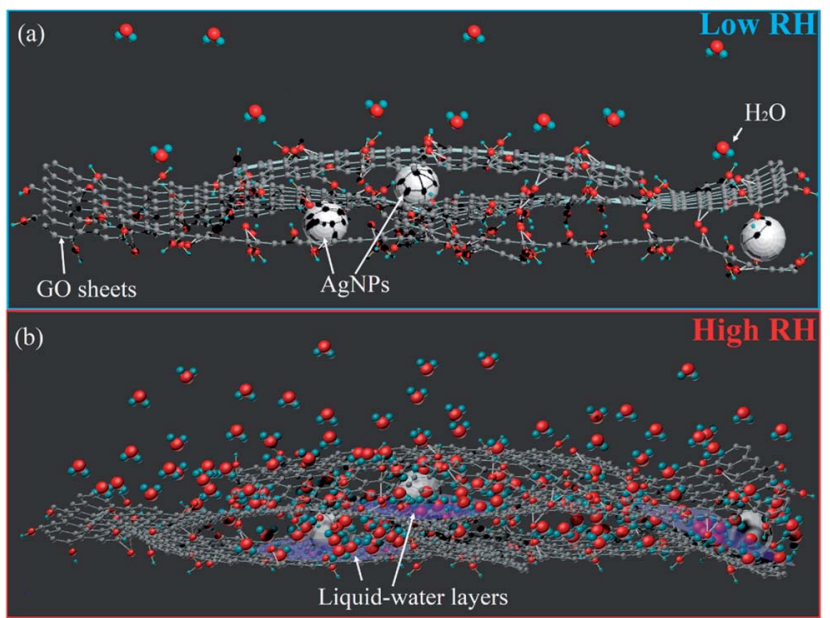

Fig. 5 Schematic of the humidity sensing mechanism under (a) low and (b) high $\mathrm{RH}$ conditions, respectively.

exhibit a liquid-like behaviour, and a fraction of them can be ionized under an electrostatic field to produce a large number of hydronium ions $\left(\mathrm{H}_{3} \mathrm{O}^{+}\right)$as charge carriers. In the bulk liquid, proton hopping between adjacent water molecules occurs in the GO films, with charge transport occurring through conductivity generated by a Grotthuss chain reaction $\left(\mathrm{H}_{2} \mathrm{O}+\mathrm{H}_{3} \mathrm{O}^{+} \rightarrow \mathrm{H}_{3} \mathrm{O}^{+}+\right.$ $\left.\mathrm{H}_{2} \mathrm{O}\right) .{ }^{36}$ Furthermore, the functional groups of $\mathrm{GO}$ can be hydrolyzed in bulk water layers, which contribute to the ionic conductivity. All these factors would lead to a sudden increase of $\gamma$; this would lead to a quite high sensitivity at high RH. In addition, the dielectric constants of water under different conditions vary. For instance, the dielectric constant of hydrated water at low $\mathrm{RH}$ is 2.2 , whereas that of free water at high $\mathrm{RH}$ is 78 . This variance enhances the sensor capacitance, thereby resulting in a high sensitivity. This finding explains the excellent humidity-sensing characteristics of the sensing materials.

The defects in GO play important roles for humidity sensing. Hence, the humidity-sensing property of $\mathrm{rGO} / \mathrm{Ag}$ with different defect concentrations can be controlled with different reduction processes of rGO. To avoid the interference of impurities, rGO was prepared through a thermal reduction method with different reduction times ${ }^{51}$ and combined with $2 \mathrm{wt} \%$ AgNPs to fabricate humidity-sensing samples. It is known that the $I_{\mathrm{D}} / I_{\mathrm{G}}$ ratio can reflect the defect concentration. Thus, the Raman characterization was carried out for the different $\mathrm{rGO} / \mathrm{Ag}$ samples, and the results are shown in Fig. 6(a). The initial capacitance and sensitivity of different $\mathrm{rGO} / \mathrm{Ag}$ samples are shown in Fig. 6(b). It can be observed that the defect concentration is inversely proportional to the reduction degree of rGO and proportional to the sensitivity of the samples. This phenomenon indicated that the defects in the samples played an important role in the adsorption of water molecules.

ii. Complex impedance spectra of the GO/Ag composite and GO. To confirm the different sorption mechanisms of sensing materials at various $\mathrm{RH}$ values, complex impedance spectra (CIS) were adopted to interpret the conductivity processes that occurred in a humidity sensor. The typical 

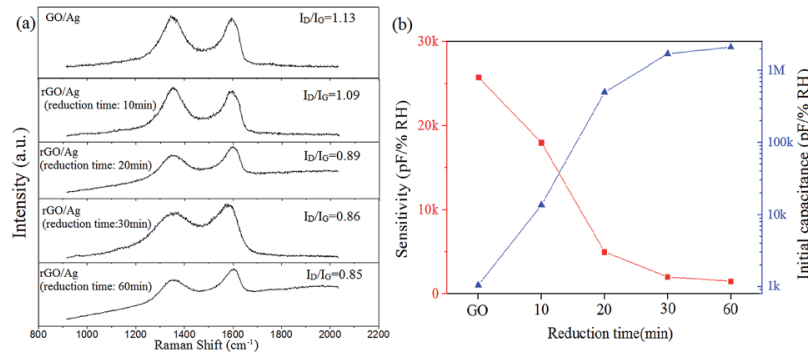

Fig. 6 (a) The Raman spectra of $\mathrm{rGO} / \mathrm{Ag}$ with different reduction times. (b) The sensitivity and initial capacitance of $\mathrm{rGO} / \mathrm{Ag}$ with different reduction times.

complex impedance spectra of $\mathrm{GO} / \mathrm{Ag}(2 \mathrm{wt} \%)$ at different $\mathrm{RH}$ values were obtained over a frequency range of $100-10000 \mathrm{~Hz}$ at a testing voltage of $1 \mathrm{~V}$ and temperature of $25^{\circ} \mathrm{C}$. The difference in the impedance spectra implies different physical phenomena for the electrical conductivity and polarization that occur in the material in the presence of water molecules. Fig. 7(a) shows the semi-circular CIS curves at low humidity. As shown in Fig. 7(b), alongside continuously increasing $\mathrm{RH}$, a line appears at high $\mathrm{RH}$ values and the semi-circular behaviour seen in the lowfrequency range is depressed. When the RH increases to $62 \%$ (Fig. 7(c)), the semicircle disappears, only leaving a line behind. The semicircle is typical of the relaxation mechanism exhibited by resistance-capacitance parallel circuits. Therefore, the semicircle results primarily from the intrinsic impedance of the material. The decrease in the curvature of the semicircle with the increasing RH reflects the decrease in the intrinsic impedance, which is related to the interaction between the sensing film and water. ${ }^{37}$ The physical phenomena of the electrical conductivity and polarization that occur in a humidity sensor are represented not only by the resistance and capacitance, but also by the diffusion and interface phenomena of ions. The straight line may stem from the ionic and/or electrolytic conductivity. Therefore, as the RH increases, the line becomes dominant in the CIS; this reflects the enhanced ionic conductivity behaviour. ${ }^{38}$

To confirm the effect of Ag nanoparticles, the CIS of pure GO was obtained and is shown in Fig. $7(\mathrm{~d}-\mathrm{f})$. Upon comparing Fig. 7 (b and e), a straight line is observed at $22 \% \mathrm{RH}$ for sensor 5 and at $54 \% \mathrm{RH}$ for sensor 1 . This phenomenon indicates that the ionic conductivity behaviour exists more easily in $\mathrm{GO} / \mathrm{Ag}$ than in pure GO at low RH levels, and this results in excellent sensitivity for the $\mathrm{GO} / \mathrm{Ag}$ composites, especially under a low humidity environment, as shown in Fig. 4. This phenomenon could be attributed to two main reasons. First, the greater number of wrinkles in the $\mathrm{GO} / \mathrm{Ag}$ composite increased the surface-to-volume ratio of the material. The water absorption capability of the GO/Ag composite was thus better than that of pure GO, as shown in Fig. 2(d). Second, as shown in Fig. 5(b), the $\mathrm{Ag}$ nanoparticles dispersed on the GO surface served as adsorption centres, which could promote the formation of bulk water layers and consequently strengthen the ion conduction for humidity sensing. Due to the abovementioned reasons, the $\mathrm{GO} / \mathrm{Ag}$ sensing films exhibited excellent humidity sensitivity, especially at low humidity levels.

iii. The effect of the Ag-GO Schottky junctions. $\mathrm{Ag}$ is a good conductor, and GO is a p-type semiconductor. The work functions of Ag and GO are 4.26 and $\sim 4.9 \mathrm{eV}$, respectively. ${ }^{39}$ Similar to the case of other semiconductors, ${ }^{40-46}$ when $\mathrm{Ag}$ is well connected to GO sheets, a Schottky junction is formed, as shown in Fig. 8(a). According to the literature, ${ }^{39}$ at low RH levels, the influence of $\gamma$ is determined mainly by the electrical conduction in a sensing material and in the Ag-GO Schottky junctions. Under a low humidity environment, the intrinsic conduction of a material is poor; thus, the electrical conduction in the $\mathrm{Ag}-\mathrm{GO}$

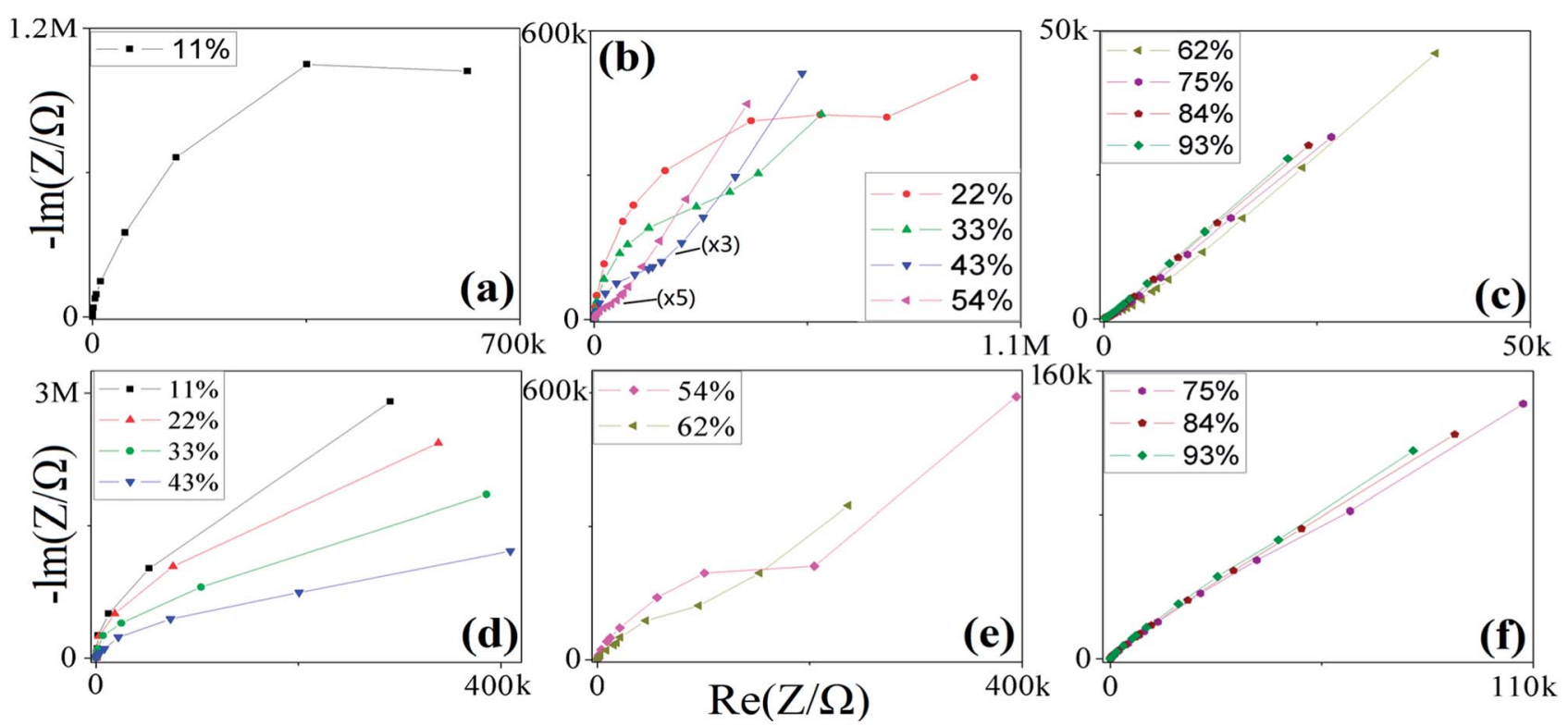

Fig. 7 Complex impedance spectra (CIS) of GO/Ag (2 wt\%) (a-c) and GO (d-f) under switching RH. 

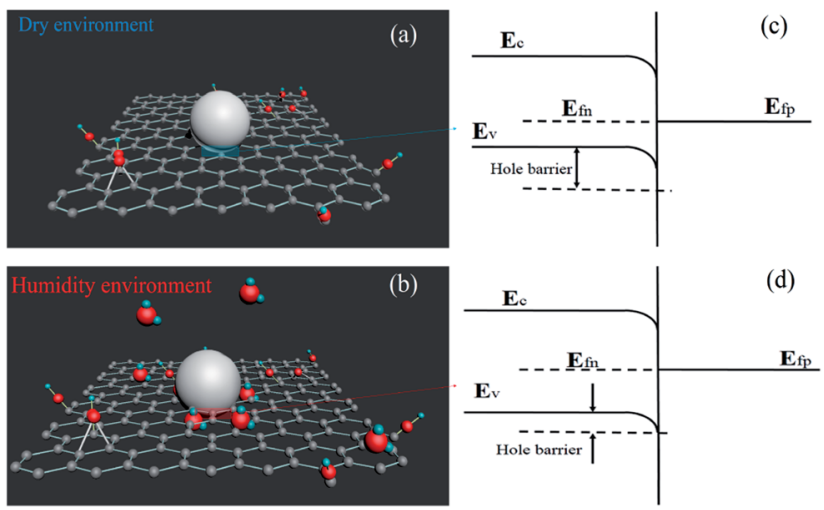

Fig. 8 GO-Ag Schottky junction and corresponding energy band diagram in $(a, c)$ dry environment and $(b, d)$ humidity environment.

Schottky junctions plays the main role. In the Ag-GO Schottky junction, the absorbed water molecules attract electrons to the surface of GO, and the work function of GO decreases, as shown in Fig. 8(b and d). Thus, the hole barrier decreases simultaneously, and consequently, this increases the conduction in the Schottky junctions. Therefore, the capacitance of $\mathrm{GO} / \mathrm{Ag}$ is significantly increased as compared to that of GO at low $\mathrm{RH}$ (Fig. 4(b)). Therefore, the Ag-GO Schottky junctions play an important role, which result in the extremely high sensitivity of $\mathrm{GO} / \mathrm{Ag}$ at low humidity.

\section{Conclusions}

A GO/Ag composite was prepared and studied as a humidity sensing material. The study results showed that the GO/Ag material displayed an ultrahigh sensitivity under the proper addition content of $\mathrm{Ag}$, and it also possessed a relatively short response time. The analysis of the humidity-sensing mechanism indicated that more wrinkles in the GO/Ag composite increased the surface-to-volume ratio of the material, and the $\mathrm{Ag}$ nanoparticles in the composite served as the adsorption centres, which could promote the formation of the bulk water layers. Moreover, the Ag-GO Schottky junctions played the main role in improving the conduction of the sensing material at low humidity. Due to the abovementioned reasons, the $\mathrm{GO} / \mathrm{Ag}$ composite exhibited excellent humidity sensitivity, especially at low humidity levels. This sensing mechanism is expected to be suitable to explain the sensing behaviour of other metal-semiconductor-material-based humidity sensors.

\section{Conflicts of interest}

There are no conflicts to declare.

\section{Acknowledgements}

This research work was supported by the National Natural Science Foundation of China (No. 61471305), Key Project of
National Natural Science Foundation of China (61731016), and Science and Technology Support Program of Sichuan Province (2016JZ0028).

\section{Notes and references}

1 J. Chu, X. Y. Peng, P. Feng, Y. Sheng and J. T. Zhang, Study of humidity sensors based on nanostructured carbon films produced by physical vapor deposition, Sens. Actuators, B, 2013, 178, 508-513.

2 U. Mogera, A. A. Sagade, S. J. George and G. U. Kulkarni, Ultrafast response humidity sensor using supramolecular nanofibre and its application in monitoring breath humidity and flow, Sci. Rep., 2014, 4, 4103.

3 D. H. Park, B. J. Kang, K. R. Cho, C. S. Shin, S. E. Cho, J. W. Park and W. M. Yang, A Study on Greenhouse Automatic Control System Based on Wireless Sensor Network, Wireless Pers. Comm., 2011, 56, 117-130.

4 G. Konvalina and H. Haick, Effect of Humidity on Nanoparticle-Based Chemiresistors: A Comparison between Synthetic and Real-World Samples, ACS Appl. Mater. Interfaces, 2011, 4, 317-325.

5 H. Liu, Z. Meng and S. Cui, A wireless sensor network prototype for environmental monitoring in greenhouses, WiCom 2007. International Conference on. IEEE, 2007, pp. 2344-2347.

6 G. J. Keeler, M. Morishita and L. Young, Characterization of complex mixtures in urban atmospheres for inhalation exposure studies, Exp. Toxicol. Pathol., 2005, 57, 19-29.

7 J. Yang, B. D. Siempelkamp, D. Liu and T. L. Kelly, Investigation of $\mathrm{CH}_{3} \mathrm{NH}_{3} \mathrm{PbI}_{3}$ degradation rates and mechanisms in controlled humidity environments using in situ techniques, ACS Nano, 2015, 9, 1955-1963.

8 E. A. Joao and A. Lovato, Effect of seed storage temperature and relative humidity on maize (Zea mays L.) seed viability and vigour, Seed Sci. Technol., 1999, 27, 101-114.

9 F. Liang, L. Luo, C. Tsang, L. Zheng, H. Cheng and Y. Li, TiO nanotube based field effect transistors and their application as humidity sensors, Mater. Res. Bull., 2012, 47, 54-58.

10 X. Liang, F. Zhang, W. Feng, X. Zou, C. Zhao, H. Na, C. Liu, F. Sun and G. Zhu, From metal-organic framework (MOF) to MOF-polymer composite membrane: enhancement of low-humidity proton conductivity, Chem. Sci., 2013, 4, 983-992.

11 K. Ketpang, K. Lee and S. Shanmugam, Facile synthesis of porous metal oxide nanotubes and modified Nafion composite membranes for polymer electrolyte fuel cells operated under low relative humidity, ACS Appl. Mater. Interfaces, 2014, 6, 16734-16744.

12 R. Ruoff, Graphene: Calling all chemists, Nat. Nanotechnol., 2008, 3, 10-11.

13 W. Chen, Z. Zhao, X. Liu, Z. Zhang and C. Suo, A capacitive humidity sensor based on multi-wall carbon nanotubes, Sensors, 2009, 9, 7431-7444.

14 S. Borini, R. White, D. Wei, M. Astley, S. Haque, E. Spigone, N. Harris, J. Kivioja and T. Ryhanen, Ultrafast graphene oxide humidity sensors, ACS Nano, 2013, 7, 11166-11173. 
15 H. Bi, K. Yin, X. Xie, J. Ji, S. Wan and L. Sun, Ultrahigh humidity sensitivity of graphene oxide, Sci. Rep., 2013, 3, 2714.

16 D. Zhang, J. Tong, B. Xia and Q. Xue, Ultrahigh performance humidity sensor based on layer-by-layer self-assembly of graphene oxide/polyelectrolyte nanocomposite film, Sens. Actuators, B, 2014, 203, 263-270.

17 S. Guo, S. Dong and E. Wang, Polyaniline/Pt hybrid nanofibers: high-efficiency nanoelectrocatalysts for electrochemical devices, Small, 2009, 5, 1869-1876.

18 B. J. Gallon, R. W. Kojima, R. B. Kaner and P. L. Diaconescu, Palladium nanoparticles supported on polyaniline nanofibers as a semi-heterogeneous catalyst in water, Angew. Chem., Int. Ed., 2007, 46, 7251-7254.

19 S. Jiang, J. Y. Chen, J. Tang, E. Jin, L. R. Kong, W. J. Zhang and C. Wang, Au nanoparticles-functionalized twodimensional patterned conducting PANI nanobowl monolayer for gas sensor, Sens. Actuators, B, 2009, 140, 520-524.

20 T. D. Dzhafarov and B. Can, Humidity-voltaic characteristics of Ag-PS-Si structures, J. Mater. Sci. Lett., 2000, 19, 21932195.

21 A. C. Power, A. J. Betts and J. F. Cassidy, Silver nanoparticle polymer composite based humidity sensor, Analyst, 2010, 135, 1645-1652.

22 J. Lu, L. Yang, A. Xie and Y. Shen, DNA-templated photoinduced silver nanowires: fabrication and use in detection of relative humidity, Biophys. Chem., 2009, 145, 91-97.

23 S. Wang, Z. Chen, A. Umar, Y. Wang, T. Tian, Y. Shang, Y. Fan, Q. Qi and D. Xu, Supramolecularly modified graphene for ultrafast responsive and highly stable humidity sensor, J. Phys. Chem. C, 2015, 119, 28640-28647.

24 Y. Dong, J. Li, L. Shi, X. Wang, Z. Guo and W. Liu, Underwater superoleophobic graphene oxide coated meshes for the separation of oil and water, Chem. Commun., 2014, 50, 5586-5589.

25 M. Wang, T. Shen, M. Wang, D. Zhang and J. Chen, One-pot green synthesis of $\mathrm{Ag}$ nanoparticles-decorated reduced graphene oxide for efficient nonenzymatic $\mathrm{H}_{2} \mathrm{O}_{2}$ biosensor, Mater. Lett., 2013, 107, 311-314.

26 Y. Yao, X. Chen, H. Guo and Z. Wu, Graphene oxide thin film coated quartz crystal microbalance for humidity detection, Appl. Surf. Sci., 2011, 17, 7778-7782.

27 A. Arena, N. Donato and G. Saitta, Capacitive humidity sensors based on MWCNTs/polyelectrolyte interfaces deposited on flexible substrates, Microelectron. J., 2009, 40, 887-890.

$28 \mathrm{~W}$. Yao, X. Chen and J. Zhang, A capacitive humidity sensor based on gold-PVA core-shell nanocomposites, Sens. Actuators, B, 2010, 1, 327-333.

29 T. Yang, Y. Yu, S. Zhu, X. Wu, X. Wang and J. Zhang, Fabrication of silver interdigitated electrodes on polyimide films via surface modification and ion-exchange technique and its flexible humidity sensor application, Sens. Actuators, B, 2015, 208, 327-333.

30 C. Zhao, M. Qin, W. Li and Q. Huang, Enhanced performance of a CMOS interdigital capacitive humidity sensor by graphene oxide, in: Proceedings of the 16th International Solid-State Sensors, Actuators and Microsystems Conference, 2011, pp. 1954-1957.

31 H. Bi, K. Yin, X. Xie, J. Ji, S. Wan, L. T. Terrones and M. S. Dresselhaus, Ultrahigh humidity sensitivity of graphene oxide, Sci. Rep., 2013, 3, 2714.

32 D. Zhang, J. Liu and B. Xia, Layer-by-Layer Self-Assembly of Zinc Oxide/Graphene Oxide Hybrid Toward Ultrasensitive Humidity Sensing, IEEE Electron Device Lett., 2016, 37, 916919.

33 G. Santoro, S. Yu, M. Schwartzkopf, P. Zhang, S. Vayalil and J. Risch, Silver substrates for surface enhanced Raman scattering: Correlation between nanostructure and Raman scattering enhancement, Appl. Phys. Lett., 2014, 104, 243107.

34 W. Geng, Q. Yuan, X. Jiang, J. Tu, L. Duan, J. Gu and Q. Zhang, Humidity sensing mechanism of mesoporous $\mathrm{MgO} / \mathrm{KCl}-\mathrm{SiO}_{2}$ composites analyzed by complex impedance spectra and Bode diagrams, Sens. Actuators, B, 2012, 174, 513-520.

35 Z. Wang, L. Shi, F. Wu, S. Yuan, Y. Zhao and M. Zhang, The sol-gel template synthesis of porous $\mathrm{TiO}_{2}$ for a high performance humidity sensor, Nanotechnology, 2011, 22, 275502.

36 C. J. T. De Grotthuss, Mémoire sur la décomposition de l'eau: et des corps qu'elle tient en dissolution à l'aide de l'électricité galvanique, 1805, vol. 58, pp. 54-57.

37 X. Song, Q. Qi, T. Zhang and C. Wang, A humidity sensor based on KCl-doped $\mathrm{SnO}_{2}$ nanofibers, Sens. Actuators, B, 2009, 138, 368-373.

38 M. Y. Su and W. Jing, Preparation and humidity sensitivity if multi-layered Zirconia thin films by sol-gel method, Sens. Lett., 2011, 9, 670-674.

39 Z. Wang, Y. Xiao, X. Cui, P. Cheng, B. Wang, Y. Gao, X. Li, T. Yang, T. Zhang and G. Lu, Humidity-sensing properties of urchinlike $\mathrm{CuO}$ nanostructures modified by reduced graphene oxide, ACS Appl. Mater. Interfaces, 2014, 6, 38883895.

40 S. Li, K. Tu, C. Lin, C. Chen and M. Chhowalla, Solutionprocessable graphene oxide as an efficient hole transport layer in polymer solar cells, ACS Nano, 2010, 4, 3169-3174.

41 R. Sellappan, J. Sun, A. Galeckas, N. Lindvall, A. Yurgens, A. Kuznetsov and D. Chakarov, Influence of graphene synthesizing techniques on the photocatalytic performance of graphene-TiO ${ }_{2}$ nanocomposites, Phys. Chem. Chem. Phys., 2013, 15, 15528-15537.

42 B. Nie, J. Hu, L. Luo, C. Xie, L. Zeng, P. Lv, F. Li, J. Jie, M. Feng, C. Wu, Y. Yu and S. Yu, Monolayer Graphene Film on ZnO Nanorod Array for High-Performance Schottky Junction Ultraviolet Photodetectors, Small, 2013, 9, 2872-2879.

43 Z. Zhang, R. Zou, G. Song, L. Yu, Z. Chen and J. Hu, Highly Aligned $\mathrm{SnO}_{2}$ Nanorods on Graphene Sheets for Gas Sensors, J. Mater. Chem., 2011, 21, 17360-17365.

44 N. Zhang, Y. Zhang, X. Pan, M. Yang and Y. Xu, Constructing Ternary CdS-Graphene-TiO ${ }_{2}$ Hybrids on the Flatland of Graphene Oxide with Enhanced Visible-Light Photoactivity 
for Selective Transformation, J. Phys. Chem. C, 2012, 116, 18023-18031.

45 G. Fan, H. Zhu, K. Wang, J. Wei, X. Li, Q. Shu, N. Guo and D. Wu, Graphene/Silicon Nanowire Schottky Junction for Enhanced Light Harvesting, ACS Appl. Mater. Interfaces, 2011, 3, 721-725.

46 J. Lin, P. Hu, Y. Zhang, M. Fan, Z. He, C. Ngaw, J. Loo, D. Liao and T. Tan, Understanding the Photoelectrochemical Properties of a Reduced Graphene Oxide- $\mathrm{WO}_{3}$ Heterojunction Photoanode for Efficient Solar-Light-Driven Overall Water Splitting, RSC Adv., 2013, 3, 9330-9336.

47 W. Shao, X. Liu, H. Min, G. Dong, Q. Feng and S. Zuo, Preparation, characterization, and antibacterial activity of silver nanoparticle-decorated graphene oxide nanocomposite, ACS Appl. Mater. Interfaces, 2015, 7, 69666973.

48 A. F. de Faria, D. S. T. Martinez, S. M. M. Meira, A. C. M. de Moraes, A. Brandelli and A. G. S. Filho, Anti-adhesion and antibacterial activity of silver nanoparticles supported on graphene oxide sheets, Colloids Surf., B, 2014, 113, 115-124.

49 P. G. Su, W. L. Shiu and M. S. Tsai, Flexible humidity sensor based on Au nanoparticles/graphene oxide/thiolated silica sol-gel film, Sens. Actuators, B, 2015, 216, 467-475.

$50 \mathrm{~S}$. Basu, Y. H. Wang and C. Ghanshyam, Fast response time alcohol gas sensor using nanocrystalline F-doped $\mathrm{SnO}_{2}$ films derived via sol-gel method, Bull. Mater. Sci., 2013, 36, 521533.

51 B. Wicklein, A. Kocjan, G. Salazar-Alvar, G. Camino, M. Antonietti and L. Bergstrom, Thermally insulating and fire-retardant lightweight anisotropic foams based on nanocellulose and graphene oxide, Nat. Nanotechnol., 2015, 10, 277-283.

52 G. Santoro, S. Yu, M. Schwartzkopf, P. Zhang, S. V. Koyiloth and J. F. Risch, Silver substrates for surface enhanced Raman scattering: Correlation between nanostructure and Raman scattering enhancement, Appl. Phys. Lett., 2014, 104, 24. 